\title{
Thrombopoietin Measurement
}

National Cancer Institute

\section{Source}

National Cancer Institute. Thrombopoietin Measurement. NCI Thesaurus. Code C74873.

The determination of the amount of thrombopoietin hormone present in a sample. 